\title{
Epidemioclinics, Etiologies and Prognosis of Cardiogene Shock State in the Intensive Care Unit of the Cardiology Department of the G-Spot Hospital
}

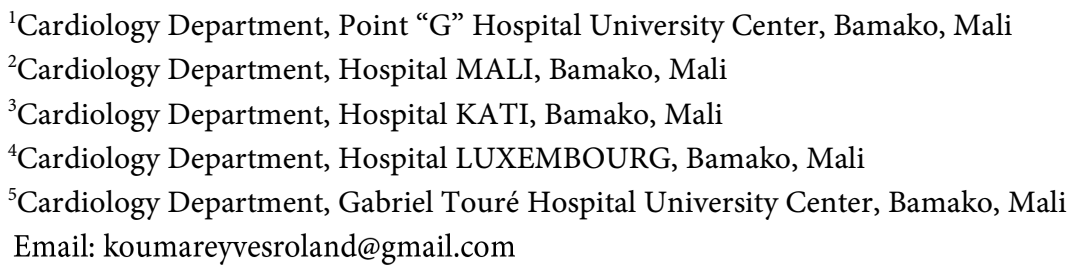

Mariam Sako1, Massama Konaté2, Boubacar Sonfo ${ }^{3}$, Samba Sidibé1, Nouhoum Diallo1, Fatoumata Diarra1, Mamadou Diakité1, Coumba Adiaratou Thiam³, Asmao Keita4, Ibrahima Sangarés, Hamidou Omar Bâ5, Youssouf Camara ${ }^{3}$, Yves Roland Koumaré1, Alou Sangaré1, Boureïma Dembélé1, Ami Diarra1, Souleymane Coulibaly'1, Ichacka Minta ${ }^{5}$

How to cite this paper: Sako, M., Konaté, M., Sonfo, B., Sidibé, S., Diallo, N., Diarra, F., Diakité, M., Thiam, C.A., Keita, A., Sangaré, I., Bâ, H.O., Camara, Y., Koumaré, Y.R., Sangaré, A., Dembélé, B., Diarra, A., Coulibaly, S. and Minta, I. (2021) Epidemioclinics, Etiologies and Prognosis of Cardiogene Shock State in the Intensive Care Unit of the Cardiology Department of the G-Spot Hospital. World Journal of Cardiovascular Diseases, 11, 20-24. https://doi.org/10.4236/wjcd.2021.111003

Received: December 7, 2020

Accepted: January 17, 2021

Published: January 20, 2021

Copyright $\odot 2021$ by author(s) and Scientific Research Publishing Inc. This work is licensed under the Creative Commons Attribution International License (CC BY 4.0).

http://creativecommons.org/licenses/by/4.0/

\begin{abstract}
Objective: The work aimed to describe the etiological and evolutionary aspects of cardiogenic shock in the intensive care unit of the cardiology department (USIC) of the G-spot hospital in Bamako, Mali. Materials and Methods: This was a descriptive cross-sectional study from January 1, 2018 to April 30, 2019 that included all patients admitted to the USIC during this period. Each patient benefited from individual data support with systematic recording of socio-demographic, clinical, complementary and therapeutic data and analyzed with the SOFTWARE SPSS 20.0 French version. Results: The study involved 40 patients out of 311 patients hospitalized in USIC, representing a hospital frequency of $12.86 \%$. Males were the most affected (60\%) with a sex ratio of 1.50 . The modal class was $41-60$ years with extremes at 18 years and 89 years. Cardiovascular risk factors were dominated by HTA $(27.50 \%)$, diabetes and tobacco, each with $22.50 \%$. The general signs were tachycardia (90\%), oxygen desaturation (77.50\%), impregnable blood pressure (62.50\%), agitation $(52.50 \%)$ and an oliguria (70\%). At the electrocardiogram the rhythm was sinus $(80 \%)$, it was an atrial fibrillation $(15 \%)$, a ventricular tachycardia $(10 \%)$ and signs of coronary ischemia (necrosis in 35\% and ST over shifted in $20 \%$ of cases). At cardiac doppler ultrasound, the left ventricle was dilated (50\%), the right cavities dilated (30\%), segmental kinetic disorder (40\%), the
\end{abstract}


left ventricular systolic function (FEVG) impaired (75\%) and valve disease (10\%). Biology noted hyper-creatinemia (65\%), hyper-glycemia (12.50\%), anemia and hyponatremia with $20 \%$ frequency each. Among etiology, ischemic heart disease accounted for $57.50 \%$ followed by pulmonary embolism $20 \%$, dilated valve cardiomyopathy $7.50 \%$ and chronic pulmonary heart $2.50 \%$. The trend in the majority of cases was unfavorable with $60 \%$ of deaths. Chronic pulmonary heart and pulmonary embolism were the deadliest with a frequency of $100 \%$ and $87.50 \%$ respectively. Conclusion: Cardiogenic shock is an infrequent condition with a high mortality of a prognosis. Ischemic heart disease is the most common etiology of the disease.

\section{Keywords}

Cardiogenic Shock, Etiology, Prognostic, USIC, Hospital Point G

\section{Introduction}

Cardiogenic shock is the most severe form of acute heart failure and is a major public health problem. This is an acute and severe failure of the heart pump, concerning systolic or diastolic function resulting in a profound alteration of tissue infusion and progressive tissue anoxia. It combines a decrease in heart rate and the stigma of tissue hypoxia, in the absence of signs of hypovolemia. The hemodynamic criteria for cardiogenic shock are:

Lower systolic blood pressure $90 \mathrm{mmhg}$, for at least 30;

Low heart rate (lower index $2.2 \mathrm{~L} / \mathrm{min} / \mathrm{m}^{2}$ );

PAPO pulmonary occlusion blood pressure greater than $15 \mathrm{mmhg}$ [1].

The GUSTO-1 study reports an incidence of 7.2\% [2]. A similar incidence (7.1\%) is observed in Worcester on a population of 9000 patients who arrived alive at the hospital [3].

The exact incidence of cardiogenic shock is difficult to measure. In Mali, although there are no national statistics on cardiogenic shock, clinical hospitalization reports have shown that it is a major public health problem. So, we proposed to carry out this etiological and prognostic study of the state of cardiogenic shock in the cardiogenic intensive care unit.

\section{Materials and Methods}

This was a cross-sectional and descriptive study from January 1, 2018 to April 30, 2019 in the Cardiological Intensive Care Unit (USIC) of The Point G Hospital and concerned all patients hospitalized during the study period.

The inclusion criteria were all patients of both sexes and ages hospitalized in the cardiogenic shock intensive care unit.

The exclusion criteria were other cardiovascular emergencies without cardiogenic shock.

Data collection and analysis each patient benefited from individual data support with systematic recording of socio-demographic, clinical, complementary 
and therapeutic data and analyzed with the SPSS 20.0 French version software.

\section{Results}

During the study period, out of 311 patients admitted to USIC, 40 patients were for cardiogenic shock, with a hospital prevalence of $12.86 \%$. The average age was $55.95 \%$ with extremes at 18 years and 80 years. The modal class was $41-60$ years old. The predominance was male (60\%) with a sex ratio of 1.50 . The pre-eminence of HTA among risk factors was classic $(27.50 \%)$, followed by diabetes and smoking with $22.50 \%$ each. The main general signs were tachycardia (90\%), oxygen desaturation (77.50\%), impregnable blood pressure (TA) (62.50\%), agitation (52.50\%), oliguria (75\%) and an alteration of consciousness (20\%) (Table 1). Heart sounds were deafened in $97.50 \%$ with a third B3 overplayed noise in $60 \%$ of cases to cardiac auscultation. The electrocardiogram recorded a sinus rhythm in $80 \%$ of cases, it was an atrial fibrillation (15\%), ventricular tachycardia with $10 \%$ frequency and signs of coronary ischemia (necrosis in 35\% and ST over shifted in $20 \%$ of cases). At cardiac doppler ultrasound the left ventricle was dilated (50\%), the right cavities dilated (30\%), segmental kinetic disorder (40\%), the left ventricular systolic function (FEVG) impaired (75\%) and valvulopathies $(10 \%)$. Biology noted hyper-creatinemia in $65 \%$ of cases, hyper-glucose in $12.50 \%$ of cases, anemia and hyponatremia with $20 \%$ frequency each and one case of hyperthyroidism (2.50\%). Etiologies were ischemic heart disease in $57.50 \%$ of cases followed by pulmonary embolism $20 \%$, valve dilated cardiomyopathy $7.50 \%$ and chronic pulmonary heart $2.50 \%$ (Table 2). In both sexes the dominant nosological group was ischemic heart disease with $15 \%$ of cases in the female sex and $42.50 \%$ in the male sex. The trend in the majority of cases was unfavorable with $60 \%$ of deaths. The case fatality rate was $79.16 \%$ for men and $31.25 \%$ for women. Chronic pulmonary heart and pulmonary embolism were the deadliest with a frequency of $100 \%$ and $87.50 \%$ respectively (Table 3 ).

Table 1. Hemodynamic signs.

\begin{tabular}{ccc}
\hline Hémodynamic signs & EFFECTIVES & FREQUENCY \% \\
\hline Agitation & 21 & 52.5 \\
Alteration of conscious & 8 & 20 \\
Oxygen desaturation & 31 & 77.5 \\
Impregnable blood pressure & 25 & 62.5 \\
Tachycardia & 36 & 90 \\
Oliguria & 30 & 75 \\
\hline
\end{tabular}

Table 2. Etiologies.

\begin{tabular}{ccc}
\hline Etiologies & EFFECTIVES & FREQUENCYE \% \\
\hline Ischemic Heart Disease (MDI) & 23 & 57.5 \\
Severe pulmonary embolism & 8 & 20
\end{tabular}




\section{Continued}

\begin{tabular}{ccc}
\hline Peri partum cardiomyopathy & 5 & 12.5 \\
Valve dilated cardiomyopathy & 3 & 7.5 \\
Chronic pulmonary heart & 1 & 2.5 \\
\hline
\end{tabular}

Table 3. Mortality and etiology.

\begin{tabular}{ccc}
\hline Etiology & \multicolumn{2}{c}{ Mortalité } \\
\hline Chronic pulmonary heart & EFFECTIVES & FREQUENCY \% \\
Severe pulmonary embolism & 1 & 100 \\
Ischemic heart disease & 7 & 87.5 \\
Valve dilated cardiomyopathy & 14 & 60.86 \\
Peri partum cardiomyopathy & 1 & 33.33 \\
TOTAL & 1 & 20 \\
\end{tabular}

\section{Discussions}

During the study period on 311 patients hospitalized in the USIC of POINT G 40 had cardiogenic shock, with a hospital prevalence of $12.86 \%$. Our rate was well below the $46.76 \%$ of Abrik [4]. This difference could be explained by the presence of a general resuscitation service at the Point $\mathrm{G}$ hospital that supports some of these patients. The average age in the series was 55.95 years; it was 60,3 years in Jean Baptiste [5]; 61 years in Bairi and Abrik [3] [4] about 3/4 of the patients were over 40 years in agreement with the rest of the literature [3] [4] [6]. The sample consisted of 24 men and 16 women with a sex ratio of 1.50 in favor of men. It was 2 at Bairi and Abrik [3] [4]. HTA, tobacco and diabetes were the main risk factors represented in accordance with the literature. Blood pressure was impregnable in $62.50 \%$ of patients, heart noises were deafened in $97.50 \%$ and tachycardia in $90 \%$ of cases. These signs show a low systolic ejection volume and therefore poor myocardial performance. There was oliguria in $75 \%$ of patients, agitation in $52.50 \%$ and impaired consciousness in $20 \%$, these manifestations are linked to low heart rate with decreased glomerular filtration and cerebral hypoperfusion. Heart rate was most often sinusal in $80 \%$, atrial fibrillation was the dominant rhythm disorder (15\%) this result is consistent with that of Bairi [3]. Electrical abnormalities related to coronary ischemia were in the majority $55 \%$ indicating the high frequency of coronary artery disease among etiology. In agreement with Bairi [3] and Sylvain [6], the majority of patients had a fraction of altered ejection (75\%) evidence of advanced myocardial suffering. In our series hyper creatinemia was the most common biological abnormality (65\%) this could be explained by functional kidney failure following low heart rate. In agreement with the rest of the literature [3] [4] [7] ischemic heart disease was the dominant etiology (57.50\%) responsible for an alteration of contraction and myocardial relaxation with decreased systolic ejection volume. Its high fre- 
quency could be explained by the prevalence of ischemic factors such as HTA, Tobacco and Diabetes. All nosological groups were represented in women in addition to peri partum cardiomyopathy which occupied $12.50 \%$ of etiologies. The occurrence of a state of shock in peri partum heart disease would be related to diagnostic delay and management. In the study, hospital mortality was $60 \%$ with a lethality of $79.16 \%$ in men and $31.25 \%$ in women. This result is consistent with the rest of the literature [1] [3] [4]. The deadliest etiologies were the chronic pulmonary heart and pulmonary embolism with frequencies at $100 \%$ and $87.50 \%$ respectively.

\section{Conclusion}

Cardiogenic shock is an infrequent condition with a high mortality of a prognosis. Ischemic heart disease is the most common etiology of the disease.

\section{Conflicts of Interest}

The authors declare no conflicts of interest regarding the publication of this paper.

\section{References}

[1] Combes, A., Leprince, P., Luyt, C.E., Bonnet, N., Trouillet, J.L., Leger, P., Pavie, A. and Chastre, J. (2008) Outcomes and Long-Term Quality-of-Life of Patients Supported by Extracorporeal Membrane Oxygenation for Refractory Cardiogenic Shock. Critical Care Medicine, 36, 1404-1411. https://doi.org/10.1097/CCM.0b013e31816f7cf7

[2] Engstrom, A.E., Cocchieri, R., Driessen, A.H., Sjauw, K.D., Vis, M.M., Baan, J., de Jong, M., Lagrand, W.K., Van der Sloot, J.A., Tijssen, J.G., de Winter, R.J., de Mol, B.A., Piek, J.J. and Henriques, J.P. (2011) The Impella 2.5 and 5.O Devise for St-Elevation Myocardial Infarction Patients Presenting with Severe and Profound Cardiogenic Shock: The Academic Medical Center Intensive Care Unit Experience. Critical Care Medicine, 39, 2072-2079. https://doi.org/10.1097/CCM.0b013e31821e89b5

[3] Jasmine, B. (2016) Etats des lieux du choc cardiogénique au service de réanimation CHU de Bejaia (mémoire de médecine. Université Abderrahmane Mira, Bejaia.

[4] Amal, A. (2017) Epidémiologie et étiopathogénie de l'état de choc cardiogénique (mémoire de médecine). Université Sidi Mohamed Ben Abdellah, Fès.

http://scolarité.fmpusmba.ac.ma/cdim/mediatheque/memoires/ememoires/101-17. pdf

[5] Dickstein, K., Cohen-Solal, A., Filippatos, G., McMurray, J.J., Ponikowski, P., Poole-Wilson, P.A., Stromberg, A., Van Veldhuisen, D.J., Atar, D., Hoes, A.W., Keren, A., Mebazaa, A., Nieminen, M., Priori, S.G., Swedberg, K., ESC Committee for Practice Guidelines (CPG). (2008) Collaborators (36) ESC Guidelines for the Diagnosis and Treatment of Acute and Chronic Heart Failure 2008: The Task Force for the Diagnosis and Treatment of Acute and Chronic Heart Failure 2008 of the European Society of Cardiology. European Journal of Heart Failure, 10, 933-989.

[6] Baptiste, S.J. (2011) Prognosis and Management of Non-Ischemic Cardiogenic Shock. Medicine Thesis, University of Henri Poincare, Nancy, No. 3740.

[7] Salem, J.E. and Aissaoui, N. (2014) Cardiogenic Shock. EMC-Cardiology, 9, 1-10. 